\title{
Functional Enteroinsular Axis in Full-Term Newborn Infants ${ }^{1}$
}

\author{
KATHERINE C. KING, ANITA OLIVEN, AND SATISH C. KALHAN \\ Division of Neonatology, State University of New York at Stony Brook and Schneider Children's Hospital, New \\ Hyde Park, New York 11042, and Division of Pediatric Metabolism and Perinatal Clinical Research Center. \\ Case Western Reserve University School of Medicine, at Cleveland Metropolitan General Hospital, \\ Cleveland, Ohio 44109
}

\begin{abstract}
The term "enteroinsular axis" refers to the enhancement of insulin release by hormones secreted from the gut. Gastric inhibitory polypeptide (GIP) is one of the major hormones that mediates this function. The purpose of the present study was to examine whether the enteroinsular axis is functional in newborn infants born at term gestation. Between d 2 and $d \mathbf{4}$ of life, glucose was infused for $2 \mathrm{~h}$ intravenously or orogastrically to 44 fullterm newborn infants, of whom 18 were appropriate for gestational age, nine large for gestational age, eight small for gestational age; nine infants were born to diabetic mothers. Glucose was infused at either $8 \mathrm{mg} / \mathrm{kg} / \mathrm{min}$ intravenously or $16 \mathrm{mg} / \mathrm{kg} / \mathrm{min}$ orogastrically to achieve similar plasma glucose concentrations. Plasma insulin and GIP concentrations were compared. Plasma GIP concentration increased significantly with enteral glucose administration in all infants but remained unchanged with parenteral glucose infusion. The responses of plasma insulin and the insulin/ glucose ratio were significantly greater in infants receiving enterally than parenterally infused glucose. However, when glucose was infused orogastrically at a lower rate $(8 \mathrm{mg}$ / $\mathrm{kg} / \mathrm{min}$ ), plasma GIP concentrations rose, but no enhancement of insulin response was detected, suggesting the importance of the role of circulating glucose in the "enteroinsular axis". The infants of diabetic mothers and the large-for-gestational-age infants had more rapid insulin response to orogastrically administered glucose, but their GIP responses were similar to that of normal infants. These findings suggest that, at term gestation, the newborn infants have a "functional" enteroinsular axis in response to glucose, i.e. the rising plasma GIP contributed in part to the enhanced insulin response to enterally infused glucose. However, the more rapid insulin response to enteral glucose in the infant of diabetic mothers probably results from the effect of intrauterine hyperglycemia. Our data could not separate the role of GIP in insulin response to enteral glucose in the infants of diabetic mothers. (Pediatr Res $25: 490-495,1989$ )
\end{abstract}

\section{Abbreviations}

GIP, gastric inhibitory polypeptide

OG, Orogastric

IV, Intravenous

Received August 8, 1988; accepted December 8, 1988.

Correspondence and reprint requests Katherine C. King, M.D., Division of Neonatology, Schneider Children's Hospital, Long Island Jewish Medical Center, New Hyde Park, NY 11042.

Supported in part by Grants HD 11089 and MO1 RR00210 from the National Institutes of Health.

$'$ A portion of this study was reported previously in $\mathrm{J}$ Pediatr Gastroenterol Nutr $19865: 220$
AGA, appropriate for gestational age

SGA, small for gestational age

LGA, large for gestational age

IDM, infant of diabetic mother

IRI, immunoreactive insulin

During the transition from fetal to neonatal life, the newborn infant initiates nutrient assimilation by the enteral route for the first time. The fetus in utero acquires its nutrients primarily via the transplacental route. Although amniotic fluid contains small amounts of nutrients such as glucose, amino acids, and ketone bodies, and the fetus swallows amniotic fluid continuously, the nutrient contribution of amniotic fluid to fetal growth is assumed to be negligible. In addition, the effect of in utero nutrient intake on gastrointestinal hormonal responses is not known. In adults, an enhanced insulin release occurs when glucose is administered enterally as compared to glucose given parenterally (1). The term "enteroinsular axis" was first used by Unger (2) in 1969 to describe this enhanced insulin response. The peptide hormone GIP has been shown to be one of the major hormones that mediates the gastrointestinally enhanced insulin release $(3,4)$.

In recent years, postnatal surges of several gastrointestinal hormones have been described in both term and preterm newborn infants $(5,6)$. The functional capacity of the enteroinsular axis and its contribution to nutrient assimilation, however, have not been defined. Lucas et al. have examined the developmental aspects of GIP secretion and its possible role in the enteroinsular axis in neonates $(7-10)$. They have demonstrated an increase in basal GIP concentrations by age $6 \mathrm{~d}$ postnatally, in both term and preterm infants who received enteral feedings. However, the associated postprandial response of GIP and insulin with feedings was not clear-cut. We have previously demonstrated a lack of enhanced insulin rise when small dose of glucose was administered orally (11), but enhancement of insulin release by enteral glucose was demonstrated with adequate glucose stimulus (12).

The present study was designed to examine whether the "enteroinsular" axis is functional at birth by comparing the plasma insulin and GIP responses to enterally or parenterally administered glucose in normal fullterm newborn infants. Furthermore, the potential effects of maternal hyperglycemic states or the deprived fetal nutritional states due to placental insufficiency on the development of hormonal responses to glucose were examined by studying the IDM and LGA and SGA infants.

\section{MATERIALS AND METHODS}

Subjects. A total of 44 fullterm newborn infants with gestational age between 38 and $41 \mathrm{wk}$ were recruited for the study. All infants fulfilled the following criteria: term gestation with no 
known intrapartum or postnatal complications; 5-min Apgar score of 7 or greater; and no known congenital anomalies, identifiable syndromes, chromosomal abnormalities, or intrauterine infections.

There were 18 AGA infants, eight SGA infants, nine LGA infants, and nine IDM. Gestational diabetes was diagnosed according to the criteria of O'Sullivan by oral glucose tolerance test during third trimester (13). Strict diabetes control during pregnancy was attempted to achieve fasting plasma glucose of less than $80 \mathrm{mg} / \mathrm{dL}$ and postprandial glucose of less than $120 \mathrm{mg} /$ $\mathrm{dL}$. Two of the nine gestationally diabetic women were treated with insulin antepartum; the others were managed by diet alone. The plasma insulin concentrations were not measured in these two infants. Although no specific maternal history or prenatal diagnosis of gestational diabetes were made in the LGA infants, their clinical features were similar to those of the infants of diabetic mothers. All infants were started on breast milk or infant formula feedings at 3-6 h of age. None of these infants were hypoglycemic or required IV glucose infusions before the study. Mean birth wt, gestational age, and the type of glucose infusions the infants received are described in Table 1.

Study design. Recruited infants were given glucose by constant rate infusions either IV or OG for $2 \mathrm{~h}$. Each infant was studied only once. The rates of glucose infusion chosen, $8 \mathrm{mg} / \mathrm{kg} / \mathrm{min}$ IV or $16 \mathrm{mg} / \mathrm{kg} / \mathrm{min}$ OG were based on our previous experience and aimed to achieve a similar rise in plasma glucose concentrations, and to achieve peak plasma glucose concentrations above $100 \mathrm{mg} / \mathrm{dL}$.

Glucose infusions at $8 \mathrm{mg} / \mathrm{kg} / \mathrm{min}$ OG or $16 \mathrm{mg} / \mathrm{kg} / \mathrm{min} \mathrm{IV}$ were also given to four infants each to compare the hormonal responses in infants receiving same rates of glucose infusions via different routes, enterally or parenterally.

The clinical protocol was approved by the Scientific Review Committee of the Perinatal Clinical Research Center and the Committee on Investigation on Human Subjects of the Cleveland Metropolitan General Hospital. Written informed consent was obtained from one or both parents after delivery of the infant and before the planned study. All studies were carried out between postnatal age of 36 to $90 \mathrm{~h}$. On the day of the glucose infusion, the infant was fed formula or breast milk at 0500 and was then kept without regular feedings until the completion of the study. Between 0800 and 0900 , the infant was stabilized under neutral thermal environment in the Perinatal Clinical Research Center. A scalp vein needle or indwelling venous cannula was placed in a peripheral vein in one of the extremities for sampling of venous blood and was kept patent with dilute heparinized saline solution $(1 \mathrm{U} / \mathrm{mL})$. For infants who would receive IV glucose infusion, an additional scalp vein needle or venous cannula was placed in a contra-lateral extremity for infusion. If glucose was to be infused enterally, an OG feeding tube $(\# 5)$ was passed into the stomach and taped in place for the duration of the study. The infant was then allowed to stabilize for $30 \mathrm{~min}$ or more after the procedure. After obtaining two blood samples at basal state 15 min apart, glucose infusion as $10 \%$ glucose solution via the IV or OG route was initiated and continued for $2 \mathrm{~h}$. Glucose infusion rates and routes of infusion for the different categories of infants are listed in Table 1.

Serial venous blood samples, $0.5-1.0 \mathrm{~mL}$, were obtained at $-15,0,15,30,60,90$, and 120 min during glucose infusion and at 30 and $60 \mathrm{~min}$ after cessation of glucose infusion. Total vol of blood removed did not exceed $4 \mathrm{~mL} / \mathrm{kg}$ body wt of the infant.

Vital signs, including heart rate, respiration, and temperature were monitored every $15 \mathrm{~min}$ by a research nurse. One of the investigators was in attendance throughout the study period. Hematocrit was determined before the study and before infant's discharge from the hospital. None of the infants had a significant change in hematocrit. At the end of the 3-h study period, gastric content was aspirated to check for residual vol and glucose concentrations. Except for one infant who had a residual gastric vol of $15-\mathrm{mL}$ containing $75 \mathrm{mg}$ of glucose, no significant residuals were noted in other infants. Within the $24 \mathrm{~h}$ of the study period, urine and stool were checked for glucose and reducing substance. No significant amount was noted in any infant.

Analytical methods. Blood samples with added aprotinin at $500 \mathrm{U} / \mathrm{mL}$ and EDTA were kept on ice. Plasma samples were separated after centrifugation and kept frozen at $-20^{\circ} \mathrm{C}$ until the time of assay for plasma IRI and GIP. Plasma glucose was determined immediately by the glucose oxidase method using a Beckman glucose analyzer (Beckman Instruments Inc., Palo Alto, CA). Unextracted plasma $(50-100 \mu \mathrm{L}$ in duplicate) was used for determinations of IRI and GIP. Plasma IRI was determined by the double antibody RIA method in the laboratory of Dr. D. S. Kerr with sensitivity and reproducibility as previously described (14).

Plasma immunoreactive GIP was determined by RIA. ${ }^{125} \mathrm{I}-$ GIP was iodinated with Iodo-gen (Pierce Chemical Co., Rockford, IL) and fractionated on a Sephadex G50 column. Antibody to porcine GIP (rabbit) was kindly provided by Dr. W. L. Go of the Mayo Clinic. Porcine GIP was used as standard. Separation of bound and free GIP was by the double antibody technique with sheep antirabbit IgG as the second antibody. The sensitivity of the assay was adequate for detection of GIP at 20-200 pg/ tube $(200-2000 \mathrm{pg} / \mathrm{mL})$. The mean overnight fasting GIP level in adults by this method was $309 \pm 113 \mathrm{pg} / \mathrm{mL}(n=21)$.

Table 1. Birth wt, gestational age, and basal concentrations of plasma glucose, insulin, and GIP in the studied infants*

\begin{tabular}{|c|c|c|c|c|c|c|c|c|}
\hline \multirow[b]{2}{*}{$\begin{array}{l}\text { Infant group } \\
\qquad(n)\end{array}$} & \multirow[b]{2}{*}{ Birth wt (g) } & \multirow[b]{2}{*}{$\begin{array}{l}\text { Gestation } \\
\text { (wk) }\end{array}$} & \multicolumn{3}{|c|}{ Glucose infusion } & \multicolumn{3}{|c|}{ Basal concentrations } \\
\hline & & & Route & $\begin{array}{c}\text { Rate } \\
(\mathrm{mg} / \mathrm{kg} / \mathrm{min})\end{array}$ & $n$ & $\begin{array}{l}\text { Glucose } \\
(\mathrm{mg} / \mathrm{dL})\end{array}$ & $\begin{array}{l}\text { Insulin } \\
(\mu \mathrm{U} / \mathrm{mL})\end{array}$ & $\begin{array}{c}\mathrm{GIP} \\
(\mathrm{pg} / \mathrm{mL})\end{array}$ \\
\hline \multirow[t]{4}{*}{ AGA (18) } & \multirow{4}{*}{$3291 \pm 278$} & \multirow{4}{*}{$39.9 \pm 0.7$} & OG & 16 & 5 & & & \\
\hline & & & IV & 8 & 5 & & & \\
\hline & & & OG & 8 & 4 & $59.0 \pm 18.4$ & $3.8 \pm 2.2$ & $483 \pm 253$ \\
\hline & & & IV & 16 & 4 & & & \\
\hline \multirow[t]{3}{*}{ SGA (8) } & \multirow{3}{*}{$2341 \pm 180$} & \multirow{3}{*}{$39.3 \pm 1.0$} & OG & 16 & 4 & \multirow{3}{*}{$52.8 \pm 15.3$} & \multirow{3}{*}{$4.4 \pm 1.6$} & \multirow{3}{*}{$661 \pm 113$} \\
\hline & & & & & & & & \\
\hline & & & IV & 8 & 4 & & & \\
\hline \multirow[t]{3}{*}{ IDM (9) } & \multirow{3}{*}{$3808 \pm 492$} & \multirow{3}{*}{$39.9 \pm 0.3$} & OG & 16 & 5 & \multirow{3}{*}{$60.9 \pm 12.3$} & \multirow{3}{*}{$7.5 \pm 4.3(7)$} & \multirow{3}{*}{$478 \pm 233$} \\
\hline & & & & & & & & \\
\hline & & & IV & 8 & 4 & & & \\
\hline \multirow[t]{3}{*}{ LGA (9) } & \multirow{3}{*}{$4178 \pm 238$} & \multirow{3}{*}{$40.2 \pm 0.7$} & OG & 16 & 5 & \multirow{3}{*}{$57.1 \pm 11.3$} & \multirow{3}{*}{$4.2 \pm 3.6$} & \multirow{3}{*}{$489 \pm 192$} \\
\hline & & & & & & & & \\
\hline & & & IV & 8 & 4 & & & \\
\hline
\end{tabular}

$*$ All values are Mean $\pm \mathrm{SD}$. 
Statistical analysis. Serial plasma concentrations of glucose, IRI, and GIP are expressed as mean \pm SD. Fasting values are the mean of -15 and 0 time values. Because of the physiologic similarities of the IDM and the LGA infants, they were combined and considered as one category. As there were no differences in response between the SGA and the AGA infants, they were also combined and analyzed as a group.

A repeated measure ANOVA was used to compare the plasma glucose, insulin, and GIP responses to glucose infusions in different groups of infants. Comparisons were made for l) differences in response based on route of glucose infusions (IV versus $O G), 2)$ differences in response between different groups of infants AGA and SGA versus IDM and LGA, and 3) difference in responses based on glucose infusion rates $16 \mathrm{mg} / \mathrm{kg} / \mathrm{min}$, or $8 \mathrm{mg} / \mathrm{kg} / \mathrm{min}$. The Scheffe post hoc test was used to examine GIP and insulin responses for factor time. $p$ values of $<0.05$ were considered significant.

\section{RESULTS}

Serial plasma glucose, insulin, and GIP concentrations of the four groups of infants. The preinfusion basal glucose concentrations were similar in all four groups of infants. This was anticipated as infants with hypoglycemia were excluded from the study. Although the basal insulin concentrations were not significantly different in the four groups of infants, two IDM and one LGA infant had preinfusion plasma insulin concentrations of 13.6, 12.2 , and $12.4 \mu \mathrm{U} / \mathrm{mL}$, respectively.

Basal plasma GIP concentrations varied greatly among the infants studied, ranging from 127 to $1050 \mathrm{pg} / \mathrm{mL}$. The SGA infants as a group tended to have higher basal GIP concentrations ( $p<0.04$ as compared to AGA infants). However, no specific factors, such as postnatal age, number of feedings postnatally or length of fasting were identified to account for the variability. Nor could a correlation be found between the basal plasma GIP concentrations and the basal plasma glucose or insulin concentrations. Because of the wide range of basal GIP concentrations in all infants, changes in GIP concentrations with glucose infusions were also expressed as incremental changes $(\triangle \mathrm{GIP})$ from the basal concentrations.

Figures 1-4 show the serial values of plasma glucose, insulin, delta GIP, and insulin/glucose ratio before, during, and after glucose infusions in infants receiving IV infusions at $8 \mathrm{mg} / \mathrm{kg} /$ $\mathrm{min}$ and $\mathrm{OG}$ glucose infusion at $16 \mathrm{mg} / \mathrm{kg} / \mathrm{min}$. Plasma glucose concentrations achieved were similar in all infants. At the termination of glucose infusions for $120 \mathrm{~min}$, a tendency toward more rapid decline in plasma glucose occurred in infants receiving glucose IV than OG.

A significant rise in plasma insulin concentrations from basal levels occurred in all infants by $60 \mathrm{~min}$ of glucose infusions and persisted to the end of the study period. OG infused glucose at $16 \mathrm{mg} / \mathrm{kg} / \mathrm{min}$ resulted in significantly higher plasma insulin responses $(p=0.0002$ for AGA + SGA infants; $p=0.0001$ for $\mathrm{IDM}+\mathrm{LGA}$ infants) as compared to IV glucose at $8 \mathrm{mg} / \mathrm{kg} /$ min; plasma glucose concentrations were comparable (Fig. 2). The relatively greater insulin responses were also seen as the significant differences in insulin/glucose ratio achieved (Fig. 3) with $\mathrm{OG}$ versus IV glucose infusions.

When the insulin responses of different groups of infants were compared, the AGA + SGA infants and IDM + LGA infants had similar insulin responses to IV glucose infusions at $8 \mathrm{mg} /$ $\mathrm{kg} / \mathrm{min}$. With OG infused glucose at $16 \mathrm{mg} / \mathrm{kg} / \mathrm{min}$, the overall insulin responses of the two groups of infants during the 180min study period were not significantly different. However, the IDM + LGA infants had a more rapid rise of insulin concentrations ( $p<0.01$ by $60 \mathrm{~min}$ ) as compared to the AGA + SGA infants.

Plasma GIP responses were distinctly different in infants receiving IV or OG glucose infusions. No significant change was observed with IV glucose, but significant rises occurred by 60
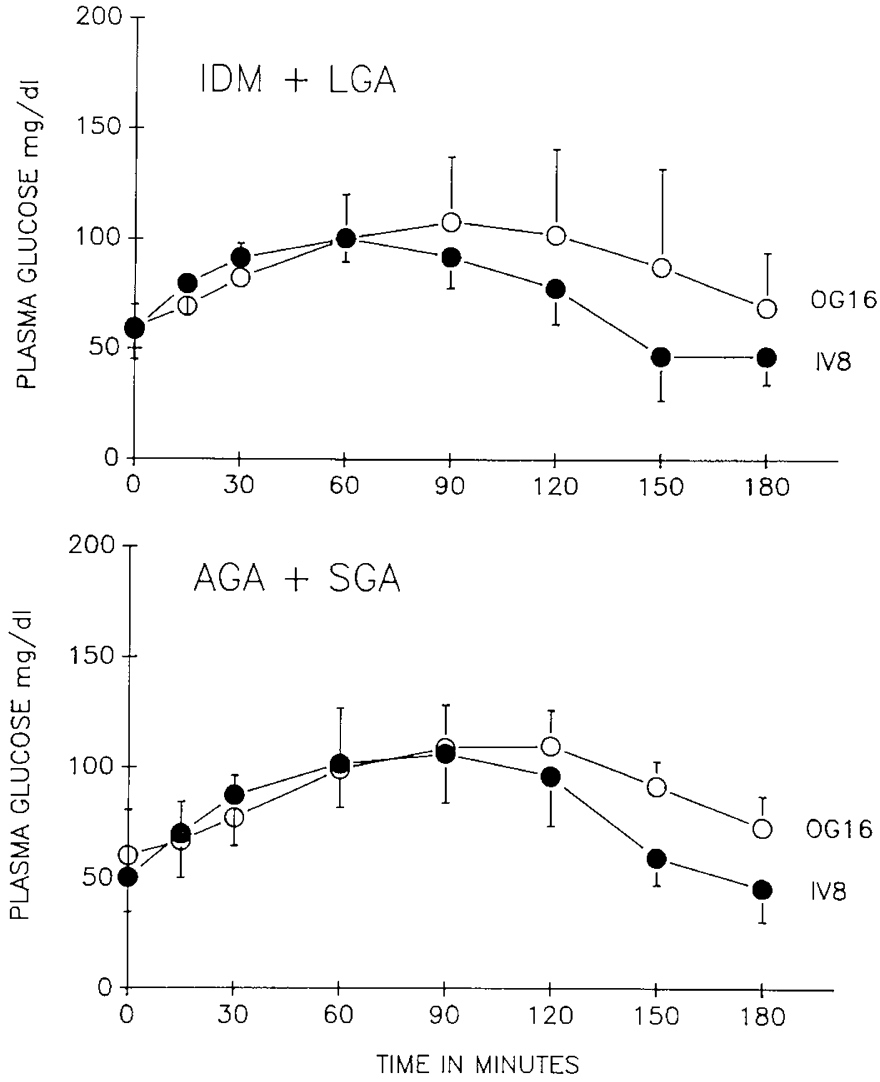

Fig. 1. Plasma glucose concentrations before, during, and after glucose infusion. $\mathrm{O}, \mathrm{OG}$ glucose infusion at $16 \mathrm{mg} / \mathrm{kg} / \mathrm{min} ; \bullet$, IV glucose infusions at $8 \mathrm{mg} / \mathrm{kg} / \mathrm{min}$. Upper panel, IDM and LGA infants. Lower panel, AGA and SGA infants.
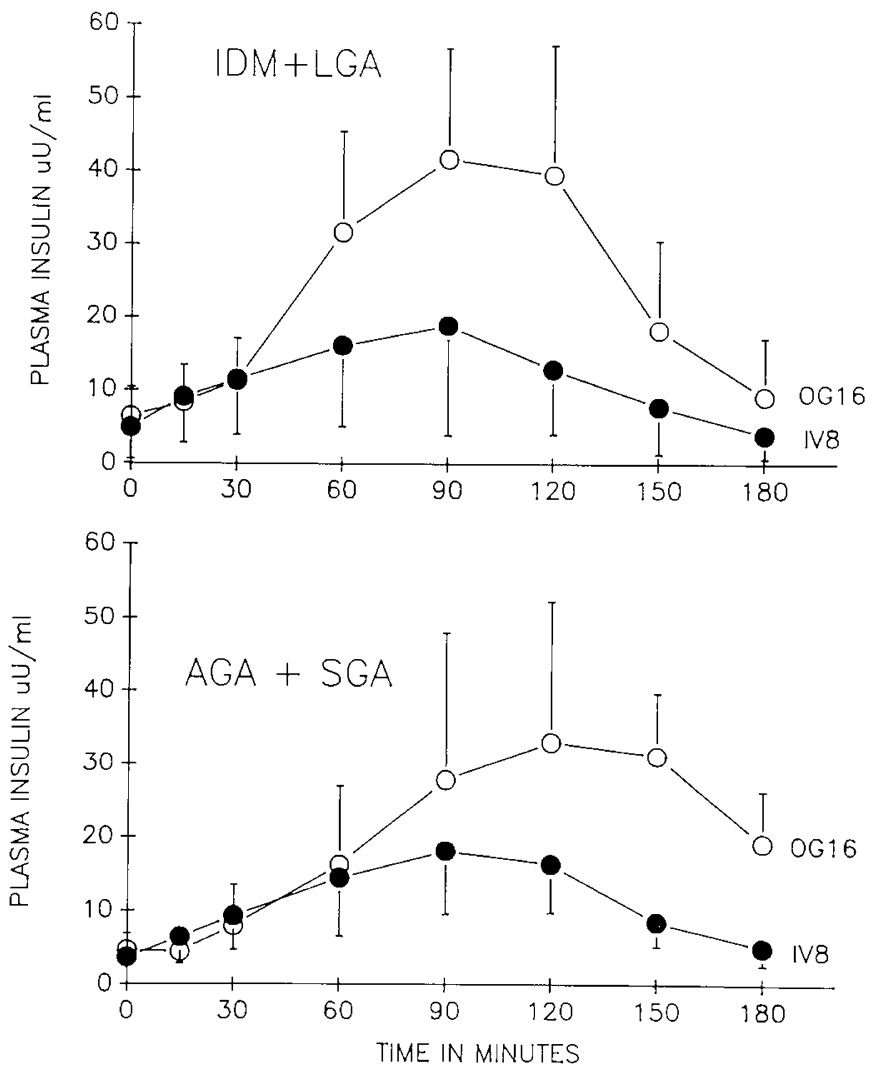

Fig. 2. Plasma insulin concentrations before, during, and after glucose infusions. Symbols, same as in Fig. 1. For AGA + SGA: OG16 vs. IV $8, p=0.0002$. For IDM + LGA: OG16 vs. IV8, $p<0.0001$. 

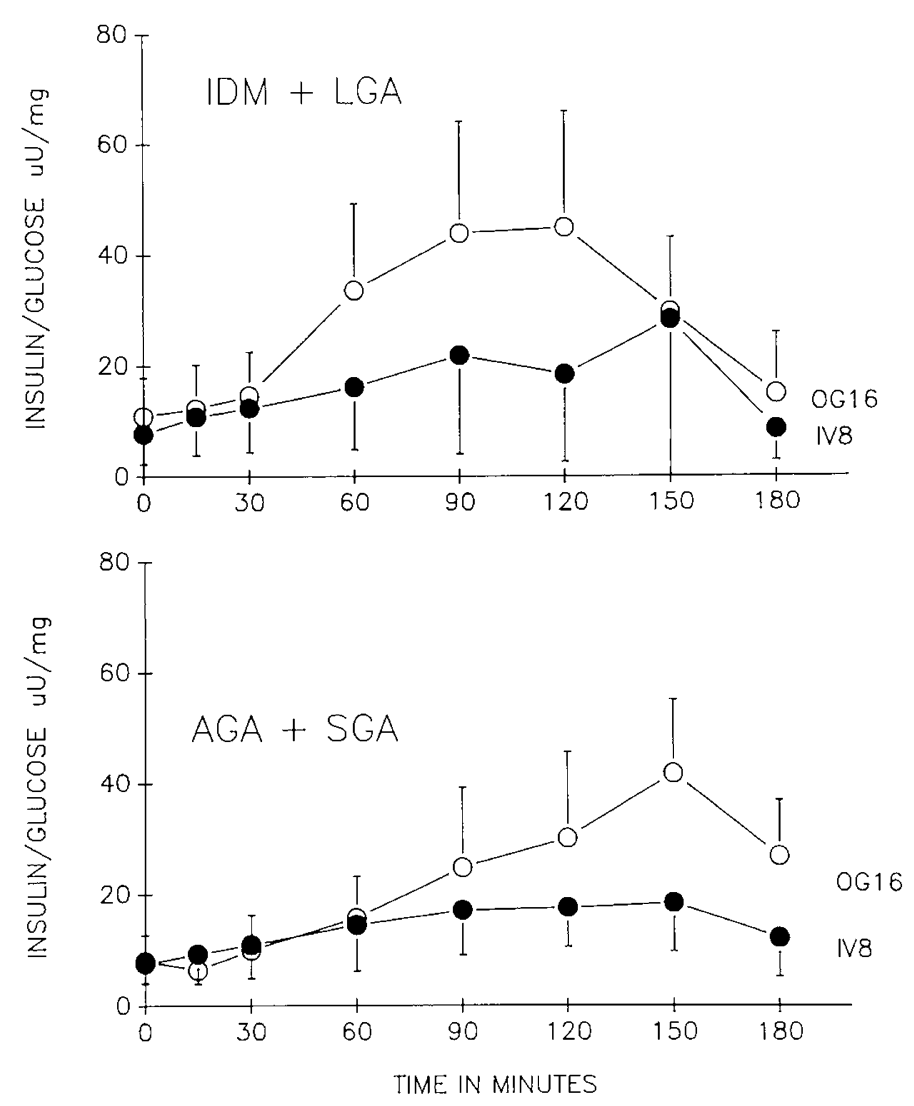

Fig. 3. Plasma insulin/glucose ratio before, during, and after glucose infusions. Symbols, same as in Fig. 1. For AGA + SGA: OG16 vs. IV8, $p<0.0001$. For IDM + LGA: OG16 vs. IV8, $p 0.0006$.
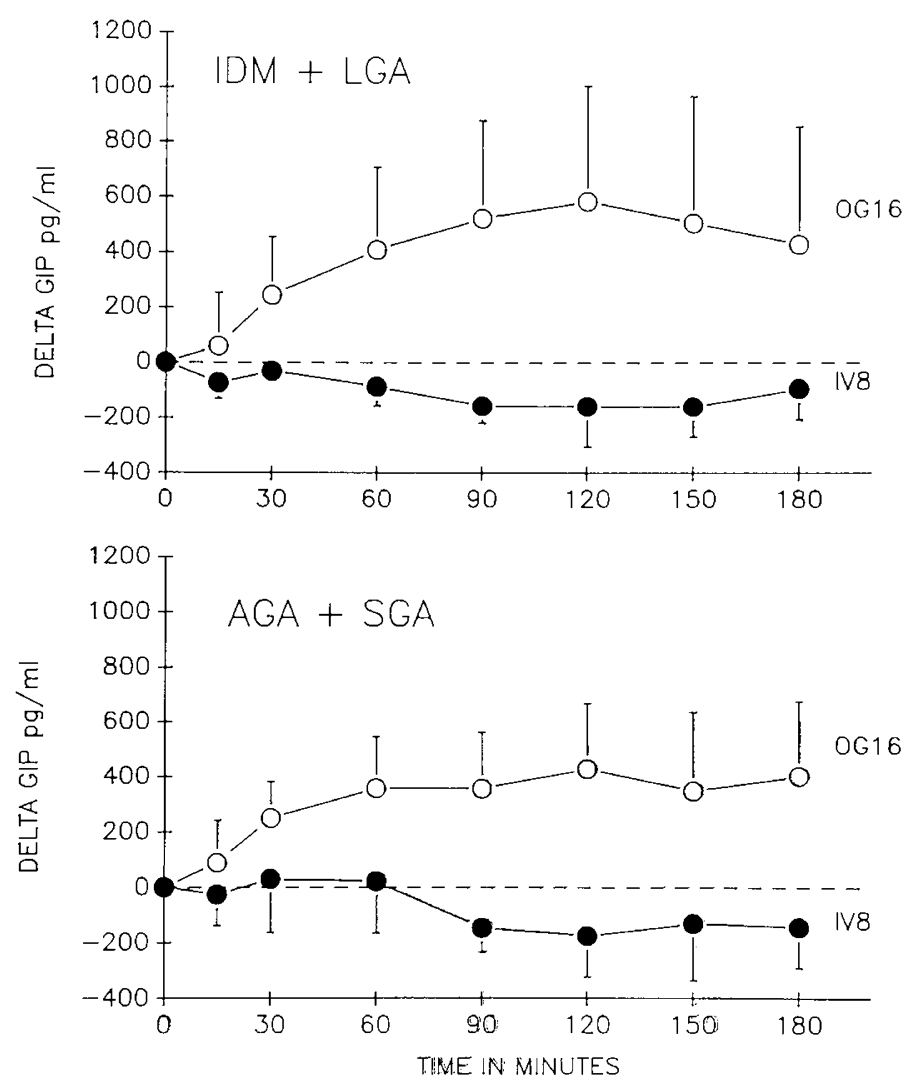

Fig. 4. Incremental GIP concentrations (GIP, as compared to preinfusion basal plasma GIP) during and after glucose infusion. Symbols, same as in Fig. 1. OG16 vs. IV \&, $p<0.0001$. min and persisted with OG glucose infusions. Analysis of GIP data utilizing absolute plasma GIP concentrations or incremental GIP levels $(\Delta G I P)$ yielded similar results. No differences in response were observed in the different groups of infants.

To examine whether the GIP-enhanced insulin response is glucose dependent, four AGA infants were given $O G$ infused glucose at low rate $(8 \mathrm{mg} / \mathrm{kg} / \mathrm{min})$, and their responses were compared to those of infants receiving a higher rate of enteral glucose $(16 \mathrm{mg} / \mathrm{kg} / \mathrm{min}$ ) (Figure 5). Figure $5 A$ shows the differences in plasma glucose achieved. Peak glucose levels were 88.7 $\pm 25.3 \mathrm{mg} / \mathrm{dL}$ in infants receiving glucose at $8 \mathrm{mg} / \mathrm{kg} / \mathrm{min}$ and $117.7 \pm 19.6 \mathrm{mg} / \mathrm{dL}$ at $16 \mathrm{mg} / \mathrm{kg} / \mathrm{min}$. Plasma GIP responses were similar; higher insulin/glucose ratios were only seen in infants with higher plasma glucose concentrations, i.e. infants receiving $O G$ infusions at $16 \mathrm{mg} / \mathrm{kg} / \mathrm{min}$ (Fig. $5 B, 5 C$, and $5 D$ ). When the insulin/glucose ratios were compared between infants receiving glucose infusions at $8 \mathrm{mg} / \mathrm{kg} / \mathrm{min}$ IV or OG, they were not significantly different $(p=0.44)$. Furthermore, the high rate of IV glucose infusion at $16 \mathrm{mg} / \mathrm{kg} / \mathrm{min}$ resulted in peak glucose concentration of $195.2 \pm 36.6 \mathrm{mg} / \mathrm{dL}$; plasma GIP concentrations did not change, and no significant enhancement in insulin/ glucose ratio was observed.

\section{DISCUSSION}

The developmental aspects of GIP and its functional role in the enteroinsular axis in the newborn infants have not been clearly defined. Lucas et al. reported that cord blood GIP concentrations were low as compared to the fasting adult (8). By 6 $\mathrm{d}$ of age, basal plasma GIP concentrations were higher in both term and preterm infants who were fed but remained low in infants not fed orally (8). However, they were unable to demonstrate a significant rise in GIP concentrations in response to a feed. Marked postprandial elevation was demonstrated by $24 \mathrm{~d}$ of age in preterm infants (8). In the present study, significant increase in GIP concentrations were demonstrated in infants receiving OG glucose infusions at both $8 \mathrm{mg} / \mathrm{kg} / \mathrm{min}$ and 16 $\mathrm{mg} / \mathrm{kg} / \mathrm{min}$. The discrepancy in findings may be best explained by the following factors: 1 ) There was great variability in basal GIP concentrations among different infants. This was observed in studies of Lucas et al. and in the current study. 2) There were differences in study designs in that cross-sectional data were obtained by Lucas et al. In contrast, serial measures from the same infant were obtained in the current study. 3) The quantity and content of feed as a stimulus may also have contributed to the differences in GIP response (9).

When comparable plasma glucose concentrations were achieved with IV or OG infusions of glucose, a significant gastrointestinally enhanced insulin response was demonstrated in all four groups of newborn infants in the present study. With the associated rise in plasma GIP concentrations during OG glucose infusion, it can be concluded that the "enteroinsular axis" is functional as early as the first 2-3 d of life postnatally. However, the pattern of response appears to be different from that of adults $(15,16)$. The peak GIP and insulin response to glucose occurred within $30 \mathrm{~min}$ in adults but occurred later in the neonates, suggesting either a delay in intestinal absorption of glucose or the slow responsiveness of GIP producing cells to glucose stimulus in the neonate.

In adults, GIP-stimulated insulin response has been shown to be glucose dependent (17). An incremental glucose rise of 17 $\mathrm{mg} / \mathrm{dL}$ over fasting, or a threshold plasma glucose concentration of $105 \mathrm{mg} / \mathrm{dL}$ or greater was required (18) for GIP-mediated enhanced insulin response to occur. The same mechanism for gastrointestinal-enhanced insulin response seems to apply in the newborn infants. As shown in Figure 5, peak glucose concentrations were $88.7 \pm 25.4 \mathrm{mg} / \mathrm{dL}$ when glucose was infused at 8 $\mathrm{mg} / \mathrm{kg} / \mathrm{min} \mathrm{OG}$; peak glucose concentrations exceeded $105 \mathrm{mg} /$ $\mathrm{kg} / \mathrm{min}$ with glucose infusion rate of $16 \mathrm{mg} / \mathrm{kg} / \mathrm{min} \mathrm{OG}$. Plasma GIP responses were similar between these two groups, whereas 

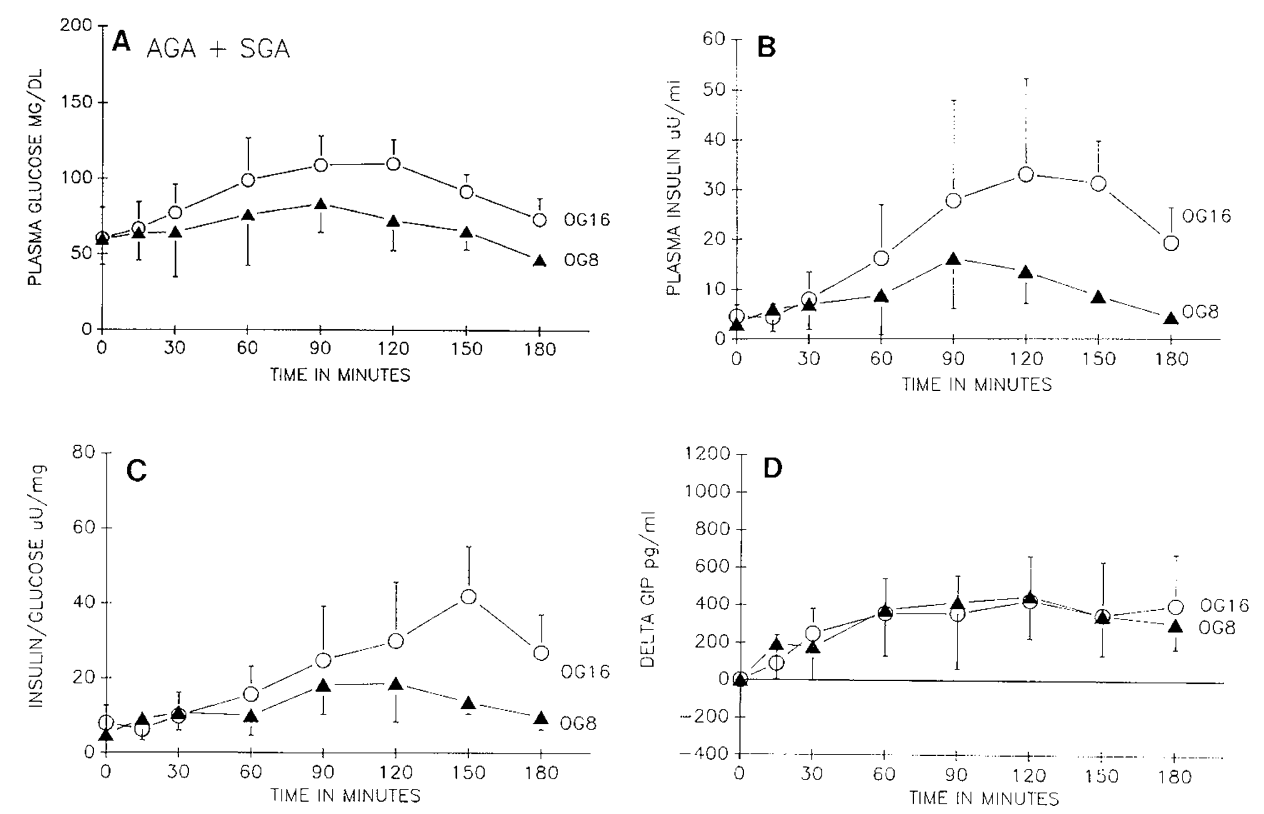

Fig. 5. A, Plasma glucose concentrations before, during and after glucose infusions. $\mathrm{O}, \mathrm{AGA}+\mathrm{SGA}$ infants (9) receiving oral gastric glucose at $16 \mathrm{mg} / \mathrm{kg} / \mathrm{min}$ for $2 \mathrm{~h}$. $\mathbf{\Lambda}$, AGA infants (4) receiving OG glucose at $8 \mathrm{mg} / \mathrm{kg} / \mathrm{min}$. $B$, plasma insulin concentrations before, during, and after glucose infusions. Symbols, same as $A$ ). $C$, insulin/glucose ratio before, during, and after glucose infusions. Symbols, same as $A$ ) OG16 vs. OG8. $p=0.0004$. $D$, incremental GIP concentrations (GIP as compared to preinfusion basal plasma GIP) during and after glucose infusions. Symbols, same as $A$ ).

enhanced insulin/glucose ratio was only observed when higher incremental plasma glucose was achieved. Previously, enhanced GIP responses to feed were described relative to postnatal age and quality of milk feedings $(8,9)$. Aynsley-Green et al. (10) have also described the differences of GIP and insulin concentrations in infants receiving continuous or bolus feeding. Higher basal hormone concentrations were observed with continuous gastric infusions, and surges of hormonal levels occurred with intermittent bolus feedings (10). As demonstrated in the current study, the adaptability of the neonatal gut with hormonal response to different quantity and quality of nutrient stimuli seemed to be remarkably efficient.

In attempting to achieve similar plasma glucose concentrations in the infants studied, twice as much glucose was infused $O G$ than IV. A delay in intestinal absorption and direct intestinal metabolism of glucose may explain partly the blunted plasma glucose rise. Smadja et al. have shown in animal studies that $50 \%$ of a gastric load of glucose was delivered to the periphery in $1 \mathrm{~h}$ and systemic glucose utilization was increased by $100 \%$ (19). The quantitative differences of hepatic glucose uptake and systemic glucose assimilation from parenterally or enterally administered glucose to neonate are still unknown. One may postulate that the gastrointestinal-stimulated insulin response may enhance glucose uptake in these infants receiving glucose via OG route. Quantitative assessment of glucose turnover will be necessary to confirm this hypothesis. The concept however may be important in considering nutrient assimilation from enteral or parenteral route in the preterm infants.

The hyperinsulinemic state of the fetus of the diabetic mother was thought to be due to maternal hyperglycemia with consequent fetal hyperglycemia. For the present study, we had postulated that maternal hyperglycemia with resultant higher amniotic fluid glucose concentrations (20) may further enhance GIP response to gastrointestinal assimilated glucose postnatally. No significant difference, however, was detected between the GIP responses of the small groups of the IDM and LGA infants as compared to the AGA and SGA infants studied. Thus, no effect of intrauterine hyperglycemia on neonatal GIP response was observed. Although gastrointestinal-enhanced insulin responses are present in these infants, quantitatively, they were not different from that of the AGA and SGA infants (by ANOVA test). It only appeared that the insulin responses of the IDM and LGA infants tends to occur more briskly without delay as compared to the AGA infants.

No hypoglycemic infants were included in the current study, and their responses to enteral or parenteral glucose remain unknown. However, if the hormonal responses to OG or IV glucose are anticipated to be as shown in the present study, then feeding glucose by mouth for management of hypoglycemia in infants of diabetic mothers requires further investigation.

Acknowledgments. The authors are grateful to the research nurses of The Perinatal Clinical Research Center for their assistance, to Monica Rubel and Edward Burket for technical assistance, to Jennifer McGorvan for preparation of the manuscript, and to Dr. Anthony Sica and Mysore Gandhi for assistance in statistical analysis.

\section{REFERENCES}

1. Mclntyre N, Holdsworth CD, Turner DS 1965 Intestinal factors in the control of insulin secretion. J Clin Endocrinol Metab 25:1317-1324

2. Unger RH, Eisentrant AM 1969 Entero-insular axis. Arch Intern Med 123:261266

3. Dupre J, Ross SA, Watson D, Brown JC 1973 Stimulation of insulin secretion by gastric inhibitory polypeptide in man. J Clin Endocrinol : 1 tab 37:826828

4. Pederson RA, Schubert HE, Brown JC 1975 The insulinotropic action of gastric inhibitory polypeptide. Can J Physiol Pharmacol 53:217-223

5. Aynsley-Green A, Bloom SR, Williamson DH, Turner RC 1977 Endocrine and metabolic response in the human newborn to first feed of breast milk. Arch Dis Child 52:291-295

6. Lucas A, Aynsley-Green A, Bloom SR 1981 Gut hormones and the first meals. Clin Sci 60:349-353

7. Aynsley-Green A, Lucas A, Bloom SR 1979 The effect of feeds on differing composition on entero-insular hormone secretion in the first hours of life in human neonates. Acta Paediatr Scand 68:265-270

8. Lucas A, Sarson DL, Bloom SR, Aynsley-Green A 1980 Developmental aspects of gastric inhibitory polypeptide (GIP) and its possible role in the enteroinsular axis in neonates. Acta Paediatr Scand 69:321-325

9. Lucas A, Boyes S. Bloom SR, Aynsley-Green A 1981 Metabolic and endocrine responses to a milk feed in six-day-old term infants: differences between breast and cow's milk formula feeding. Acta Paediatr Scand 70:195-200

10. Aynsley-Green A, Adrian TE, Bloom SR 1982 Feeding and the development of enteroinsular hormone secretion in the preterm infants: effects of continuous gastric infusions of human milk compared with intermittent boluses. Acta Paediatr Scand 71:379-383

11. King KC, Schwartz R, Yamaguchi K, Adam PAJ 1977 Lack of gastrointestinal 
enhancement of the insulin response to glucose in newborn infants. J Pediatr 91:783-786

12. Oliven A, King KC, Kalhan SC 1986 Gastrointestinal enhanced insulin release in response to glucose in newborn infants. $J$ Pediatr Gastroenterol Nutr 5:220-225

13. O'Sullivan JB, Mahan CM 1964 Criteria for the oral glucose tolerance test in pregnancy. Diabetes 13:278-285

14. Kerr DS, MCG Stevens, HM Robinson 1978 Fasting metabolism in infants. I. Effect of severe undernutrition on energy and protein utilization. Metabolism 27:411-435

15. Miller LJ, Malagelada JR, Go VLW 1978 Intestinal nutrient influence on the entero-insular axis. J Clin Endocrinol Metab 47:1009-1014

16. Williams RH, May JM, Bierbroeck JB 1981 Determinants of gastric inhibitory polypeptide and insulin secretion. Metabolism 30:36-40

17. Anderson DK, Elahi D, Brown JC, Tobin JD, Andres R 1978 Oral glucose augmentation of insulin secretion. J Clin Invest 62:153-161

18. McCoullough AJ, Miller LJ, Service FJ, Go VLW 1983 Effect of graded intraduodenal glucose infusions on the release and physiological action of gastric inhibitory polypeptide. J Clin Endocrinol Metab 56:234-241

19. Smadja C, Morin J, Ferre P, Girard J 1988 Metabolic fate of a gastric glucose load in unrestrained rats bearing a portal vein catheter. Am $J$ Physiol 254:E407-E413

20. Pochopien DJ 1974 Urea and glucose concentrations of amniotic fluid during pregnancy. In: Natelson S, Scommegna A, Epstein MB (eds) Amniotic Fluid, Physiology, Biochemistry, and Clinical Chemistry. New York: John Wiley \& Sons, New York

\section{Announcement}

\section{Call For Papers}

\section{Artificial Intelligence in Medicine}

The next two volumes of the new international quarterly journal Artificial Intelligence in Medicine, Vol. 2 (1990) and Vol. 3 (1991), will be devoted to studies in medical knowledge engineering. Papers on all aspects of medical expert systems, including their designing, application and evaluation, are welcome. Contributions should be sent to the editor: Professor K. S. Zadeh, University of Münster Hospital, Department of Medical Informatics, Münster, West Germany 4400.

Electronic manuscripts are preferred. Details and Instructions for Authors may be obtained from the publisher: Burgverlag, P.O. Box 1247, Tecklenburg, West Germany 4542. 